\title{
Liter per Minute per Milligram per Day
}

National Cancer Institute

\section{Source}

National Cancer Institute. Liter per Minute per Milligram per Day. NCI Thesaurus. Code C120751.

A unit of concentration equal to liter per minute divided by milligram per day. 